\section{PREOPERATIVE AND \\ INTRAOPERATIVE \\ CONSIDERATIONS FOR \\ RADIAL ARTERY ANOMALIES \\ IN CORONARY ARTERY \\ BYPASS GRAFTING \\ To the Editor:}

We read with great interest the recent description of an unusual radial artery anomaly by Chong and De Souza. ${ }^{1}$ A more superior radial graft patency over the saphenous vein is confirmed via a randomized controlled trial and is likely to encourage its use as a conduit of choice after the left internal thoracic artery (LITA). ${ }^{2}$ We regularly use the radial artery as a conduit in our practice and have not encountered such an anomaly in our experience with more than 900 patients to date (single surgeon). ${ }^{3}$

Because of its abnormal anatomic course, the harvested radial graft was too short to reach its target circumflex region, and a vein graft was used instead (the LITA was grafted to the left anterior descending artery and radial to diagonal artery). A similar situation in the absence of a suitable saphenous vein graft, especially in patients with bilateral vein stripping, may preclude a complete myocardial revascularization. Alternatives include the bilateral internal thoracic arteries or the radial artery from the opposite arm. However, the latter option will be compromised by an uncertainty of whether the opposite radial artery will also follow a similar abnormal course.

\footnotetext{
The Editor welcomes submissions for possible publication in the Letters to the Editor section that consist of commentary on an article published in the Journal or other relevant issues. Authors should: - Include no more than 500 words of text, three authors, and five references. - Type with double-spacing. - See http://jtcs.ctsnetjournals.org/misc/ifora.shtml for detailed submission instructions. - Submit the letter electronically via jtcvs.editorialmanager.com. Letters commenting on an article published in the JTCVS will be considered if they are received within 6 weeks of the time the article was published. Authors of the article being commented on will be given an opportunity of offer a timely response ( 2 weeks) to the letter. Authors of letters will be notified that the letter has been received. Unpublished letters cannot be returned.
}

In some patients in whom bilateral internal thoracic artery use is less than ideal, an enticing option will be a horseshoe anastomotic network using the LITA and radial artery, as described by Aguero and colleagues. ${ }^{4}$ With this technique, each end of the radial artery is anastomosed in an end-to-side fashion to the diagonal and obtuse marginal branches and in a side-to-side fashion to the LITA. This permits a complete revascularization of the left coronary system with the 2 available arterial conduits without requiring an additional piece of graft.

The relevance of an unusual anatomy is important not only in conduit harvesting in coronary artery bypass grafting but also in retrieving a viable free flap and preventing donor site complication in reconstructive surgery. The role of preoperative vascular investigation in the latter is controversial. Likewise, no consensus exists in cardiac surgery. Routine preoperative investigations, apart from the Allen's test, are unlikely to be cost-effective. ${ }^{3}$ Doppler ultrasound scan has been advocated to supplement the Allen's test when the latter is equivocal, but will not demonstrate the anomaly described. Highresolution multidetector computed tomography angiography is a useful, noninvasive imaging procedure that has been evaluated as a feasible preoperative investigation to assess the radial artery for its anatomic variation, atherosclerotic involvement, and collateralization with the ulnar artery. ${ }^{5}$ In the face of possible radial artery anomaly, additional investigation to help intraoperative planning, especially when the choice of conduit is lacking (as in previous bilateral saphenous vein stripping), may need further exploration.

$$
\begin{array}{r}
\text { Edward W. K. Peng, MRCS } \\
\text { Pradip K. Sarkar, FRCS } \\
\text { Department of Cardiothoracic } \\
\text { Surgery } \\
\text { Northern General Hospital } \\
\text { Sheffield Teaching Hospitals NHS } \\
\text { Trust } \\
\text { Sheffield, United Kingdom }
\end{array}
$$

\section{References}

1. Chong CF, De Souza A. Significance of radial artery anomalies in coronary artery bypass graft surgery. J Thorac Cardiovasc Surg. 2008;135:1389-90.

2. Collins P, Webb CM, Chong CF, Moat NE. Radial artery versus saphenous vein patency (RSVP) Trial Investigators. Radial artery versus saphenous vein patency randomized trial. five-year angiographic follow-up. Circulation. 2008;117:2859-64.

3. Asif M, Sarkar P. Re: Is the Allen test reliable enough? Eur J Cardiothorac Surg. 2008;33:1161.

4. Aguero OR, Navia JL, Navia JA, Mirtzouian E. A new method of myocardial revascularization with the radial artery. Ann Thorac Surg. 1999;67: 1817-8.

5. Dogan OF, Karcaaltincaba M, Duman U, Akata D, Besim A, Boke E. Assessment of the radial artery and hand circulation by computed tomography angiography: a pilot study. Heart Surg Forum. 2005; 8:E28-33.

doi:10.1016/j.jtcvs.2008.08.070

\section{Reply to the Editor:}

I thank Drs Peng and Sarkar for their comments regarding the importance of awareness of radial artery (RA) anomalies when considering harvesting the conduit for coronary artery bypass grafting. Although the incidence of RA anomalies reported by McCormack and colleagues ${ }^{1}$ in a study of 750 cadaveric limbs was on the order of $18 \%$, most of these were due to high origin of the RA from the axillary $(11.5 \%)$ or brachial artery $(77 \%)$. In contrast, the anomaly reported in our study, an abnormally low origin of the RA behind the pronator teres muscle, is rare, with a prevalence of probably less than $0.01 \%$. McCormack and colleagues ${ }^{1}$ and Weathersby ${ }^{2}$ encounter this form of anomaly in a total of 1158 limbs studied.

In the anomaly that we have reported, the full length of the RA, albeit shorter than normal, can still be harvested by dividing the pronator teres and following the artery behind the muscle up to its origin from the brachial artery. Faced with a shortened conduit, one solution would be to alter the grafting strategy by grafting the conduit to a more proximal coronary lesion, such as a proximal stenosis in the diagonal artery, or by anastomosing the proximal end of the RA to the 